\section{Multidisciplinary \\ SCIENTIFIC JOURNAL OF \\ MARITIME RESEARCH}

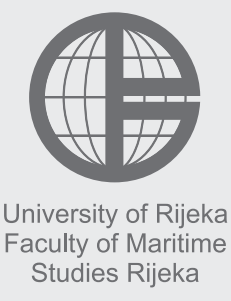

\section{Multidisciplinarni \\ znanstveni časopis \\ POMORSTVO}

\title{
Wind farm service vessels concept design. Part 1 - Mathematical model
}

\author{
Oleksandr V. Bondarenko
}

Department of Theory and Ship Design, Institute of Naval Architecture, Admiral Makarov National University of Shipbuilding, 9, Geroev Stalingrada Av., Mykolaiv, Ukraine, e-mail: Oleksandr.Bondarenko@nuos.edu.ua

\begin{abstract}
This paper describes the process of a conceptual design of the Wind farm service vessel. The optimization problem of the choice of principal particulars of the WFSV is formulated. For her decision, a genetic algorithm is used. A minimum of costs on repair and maintenance of wind farm is chosen as the objective function. The methodology of the optimization process such as objective function, design variables and used constraints is described. Furthermore, a mathematical model considering dimensions, powering, mass, stability, sea keeping and cost calculation is developed. Methodology of the estimation of economic efficiency, basis of what is made by the methods of statistical design, theory of probability and theory of reliability, is worked out. Software is worked out, giving an opportunity to visualize the process of functioning of the WFSV and wind farm. The methodology may be used in the conceptual design stages for selecting the main dimension of the WFSV.
\end{abstract}

\section{ARTICLE INFO}

Original scientific paper

Received 9 September 2016

Accepted 4 December 2017

\section{Key words:}

Wind farm service vessel

Concept design

Main dimensions

Mathematical model

Genetic algorithm

Efficiency

Optimization

\section{Introduction}

In the present day global community, great attention is paid to the development of renewable energy sources. One of the promising options is building offshore wind farms (WF). Development of the offshore wind energetics is also of interest for the shipbuilding industry, since providing assembling, commissioning, maintenance and repair requires a whole range of vessels: foundations and wind turbines installing vessels, substation assembling vessels, cable laying vessels, special personnel transfer vessels, hydrographic vessels, service vessels, underwater vehicles etc.

Expenses associated with maintenance and repair of turbines constitute a considerable proportion of the cost of the WF generated electricity. Transferring maintenance technicians, their tools, materials, equipment, spare parts and other goods to the turbines, carrying out inspection activities, performing diving operations and preventive measures, and cleaning turbine columns are performed by special vessels - wind farm service (support) vessel (WFSV). These vessels can also be adapted to transfer fuel for the WF generator. In addition to these functions, WFSV are used to provide work of cable laying vessels and support diving operations during the WF installation.

One of the ways of reducing the cost of energy is cutting the WFSV building and operation cost by optimizing their basic technical and operational characteristics.

\section{Problem definition}

Designing WFSV is associated with some difficulties and requires the development of mathematical models for the determination of their main dimensions, assessment of efficiency and safety of their operation. For this purpose, it is advisable to use the advanced framework of simulation modeling, as well as the theory of reliability, safety and risk [1, 6, 11-13].

In view of the novelty and the lack of substantial experience in the WFSV designing and building, the problem of the selection of the optimal principal particulars of the offshore wind farm service vessels is poorly studied and urgent. 
The analysis of literature carried out by the author has shown that there are hardly any publications on the subject matter. Applying traditional techniques for designing high-speed passenger catamarans does not seem possible due to the specific nature of the WFSV operation. At the same time, some algorithms of these methods can be used in the selection of the optimal principal particulars of the wind farm service vessels.

A solution to some issues related to the design and research of the WFSV operation efficiency can be found in $[2,4]$. Particularly, [4] describes the algorithm for the selection of the optimal WFSV hull shape, and [2] shows the model for the assessment of efficiency and selection of the best WFSV option from a given set. However, these studies do not address the question of the selection of the optimal main dimensions of the vessel.

Based on the above stated fact, it can be concluded that there is the need for developing a comprehensive technique for the selection of the optimal WFSV principal particulars which would take into account the special features of their operation.

\section{Methodology}

The previously performed analysis of the architectural and structural types of the built wind farm support vessels has shown that more than $86 \%$ of them were catamarans. Therefore, this paper considers the development of the technique for the selection of the optimal main dimensions of WFSV of the catamaran type at the preliminary stage.

It is reasonable to perform the selection of the optimal WFSV main dimensions by means of solving the optimization problem in the following formulation:

$$
\begin{aligned}
& F(X, C) \rightarrow \min (\max ), \\
& X \in D_{i} \subset R^{n}, \\
& D_{i}=\left\{X \in R^{n} \mid g_{j}(X, C) \geq 0, \quad j \in[1, p], g_{l}(X, C)=0,\right. \\
& l \in[p+1, k]\},
\end{aligned}
$$

where is:

$F(X, C)$ - objective function;

$C\left(C_{1}, \ldots, C_{m}\right)$ - vector of the parameters forming the design task;

$m$ - number of the $C$ vector parameters;

$X\left(x_{1}, \ldots, x_{n}\right)$ - vector of independent variables,

$n$ - number of independent variables;

$k$ - total number of the optimization problem's constraints;

$p$ - number of the optimization problem's constraints in the form of inequations,

$D_{i}$ - represents a set of allowable values for the design variable $i$;

$R^{n}$ - real-valued function in $n$ variables.
The aim of solving the optimization problem is to minimize the cost repair and maintenance of wind farm:

$$
F(X, C)=C_{P}+C_{S}+C_{O}+C_{L}
$$

where is:

$C_{P}$ - cost of spare parts and other materials necessary for the turbine repair or maintenance [GBP];

$C_{S}$ - cost of service (personnel transfer) [GBP];

$C_{O}$ - cost of electricity lost due to the turbine downtime [GBP];

$C_{L}$ - total cost of extra labor required for the repair [GBP].

The cost of electricity lost due to the downtime of the $i$-th turbine is determined according to the work data [5] using the following formula:

$$
C_{0}(i)=D_{F}(i) \bar{P}_{\text {out }} \overline{E P R}
$$

where is:

$D_{F}(i)$ - time of the turbine failure [hours];

$\bar{P}_{\text {out }}$ - average output wind power of turbine within duration of failure $[\mathrm{kWh}]$;

$\overline{E P R}$ - average energy purchase rate, within duration of failure $[\mathrm{GBP} / \mathrm{kWh}]$.

The cost of works related to the fault repair is determined as follows

$$
C_{L}(i)=D_{F}(i) \cdot N_{C} \cdot M H R
$$

where is:

$N_{C}$ - required number of repair technicians (Table 1);

MHR - man-hour rate [GBP/hours].

The value of the cost of service:

$$
C_{S}=C_{d p}+C_{r m}+C_{s a l}+C_{i n s}+C_{a d m}+\sum_{i=1}^{m} C_{f u e l}(i)
$$

where is:

$C_{d p}$ - depreciation costs [GBP];

$C_{r m}$ - repairing and maintenance costs [GBP];

$C_{\text {sal }}$ - crew costs [GBP];

$C_{\text {ins }}$ - insurance cost [GBP];

$C_{\text {adm }}$ - administration cost [GBP];

$C_{\text {fuel }}(i)$ - cost of fuel and lubricating oils [GBP];

The vector of independent variables includes the following WFSV characteristics: length of the vessel hull $x_{1}=$ $L_{H}$, length-displacement ratio $x_{2}=l=L_{W L} / \nabla^{1 / 3}$, breadth to draft ratio of the demi-hull $x_{3}=B_{X} / d$, the ratio of the hull spacing to the length of waterline $x_{4}=B_{S} / L_{W L}$, length to breadth ratio of the demi-hull $x_{5}=L_{W L} / B_{X^{\prime}}$ maximum speed of the vessel $x_{6}=V_{s^{\prime}}$ number of technicians $x_{7}=N_{p a s^{\circ}}$.

The set of allowable values $D_{i}$ is formed on the basis of the system of direct and functional constraints organized as the inequations $g(X, C) \geq 0$. The direct constraints are imposed directly on the components of the vector of independent variables and the components of the input parameters:

$$
x_{i}^{\min } \leq x_{i} \leq x_{i}^{\max }, i=1, \ldots, n
$$


Table 1 Basic Standards for the Maintenance/Repair of the Wind Turbine Parts [2]

\begin{tabular}{|c|c|c|c|c|}
\hline $\begin{array}{c}\text { Failure } \\
\text { Category }\end{array}$ & $\begin{array}{l}\text { Failure Rate, } \\
\text { [times/year] }\end{array}$ & $\begin{array}{c}\text { Repair Time } \\
\text { [hours] }\end{array}$ & $\begin{array}{c}\text { Required } \\
\text { Technicians }\end{array}$ & $\begin{array}{c}\text { Repair Cost } \\
\text { [GBP] }\end{array}$ \\
\hline Manual restart & 8.79 & 1 & 2 & - \\
\hline Blades & 1.48 & 8 & 2 & 20,300 \\
\hline \begin{tabular}{|l|} 
Pitch System \\
\end{tabular} & 0.08 & 5 & 2 & 7,150 \\
\hline Hub & 0.185 & 4 & 2 & 4,300 \\
\hline Main Shaft \& Bearings & 0.185 & 4 & 2 & 14,000 \\
\hline High speed shaft & 0.19 & 3 & 2 & 3,250 \\
\hline Mechanical Brake & 0.04 & 2 & 2 & 2,500 \\
\hline Generator & 0.08 & 4 & 2 & 12,000 \\
\hline Control system & 0.24 & 4 & 2 & 4,150 \\
\hline Yaw System & 0.12 & 3 & 2 & 10,800 \\
\hline
\end{tabular}

The functional constraints include requirements for the WFSV technical properties:

$$
A_{j}(X) \leqq a_{j}
$$

where $A_{j}(X)$ and $a_{j}$ - are the calculated value and the required value of the vessel qualities correspondingly.

The following constraints are considered: requirements for intact stability, rolling period, equality between mass and displacement, maximum value of draft, maximum value of breadth, motion sickness indexes (MSI) and al.
It is advisable to solve the problem by using a genetic algorithm [10]. Choosing this method of optimization is accounted for its ability to work with many variables, simultaneous search from several space points and the effectiveness of search, i.e. the high speed of finding an optimal solution. Thus, the mathematical model of the vessel is suggested. It includes the following components: main dimensions, propulsion, mass, trim and stability, building cost and efficiency. The model is based on the achievements [3,7] improved by the author as applied to vessels of the WFSV type, as well as regression curves obtained independently. The block diagram of the model is shown in Figure 1.

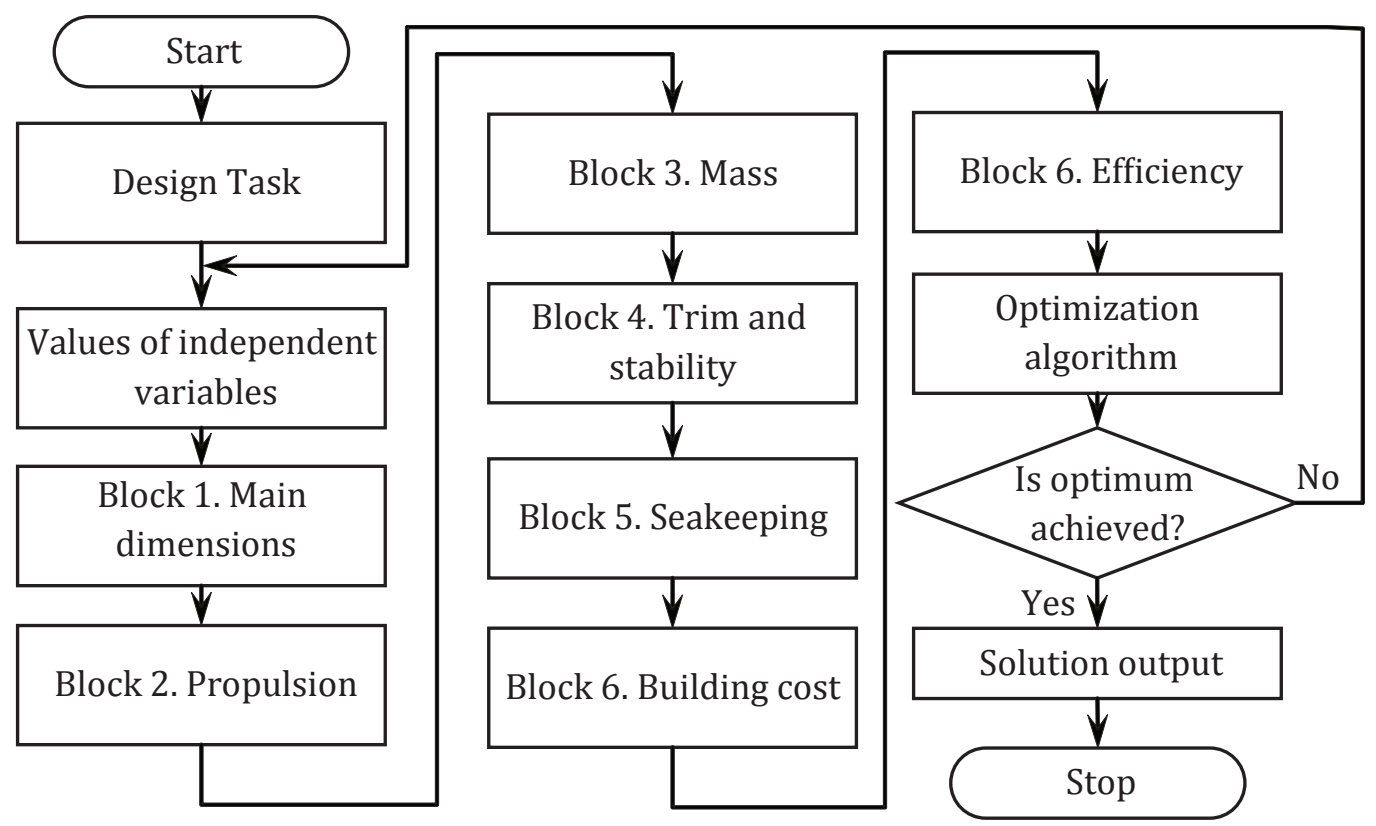

Figure 1 Block Diagram of the Mathematical Model of the Vessel 


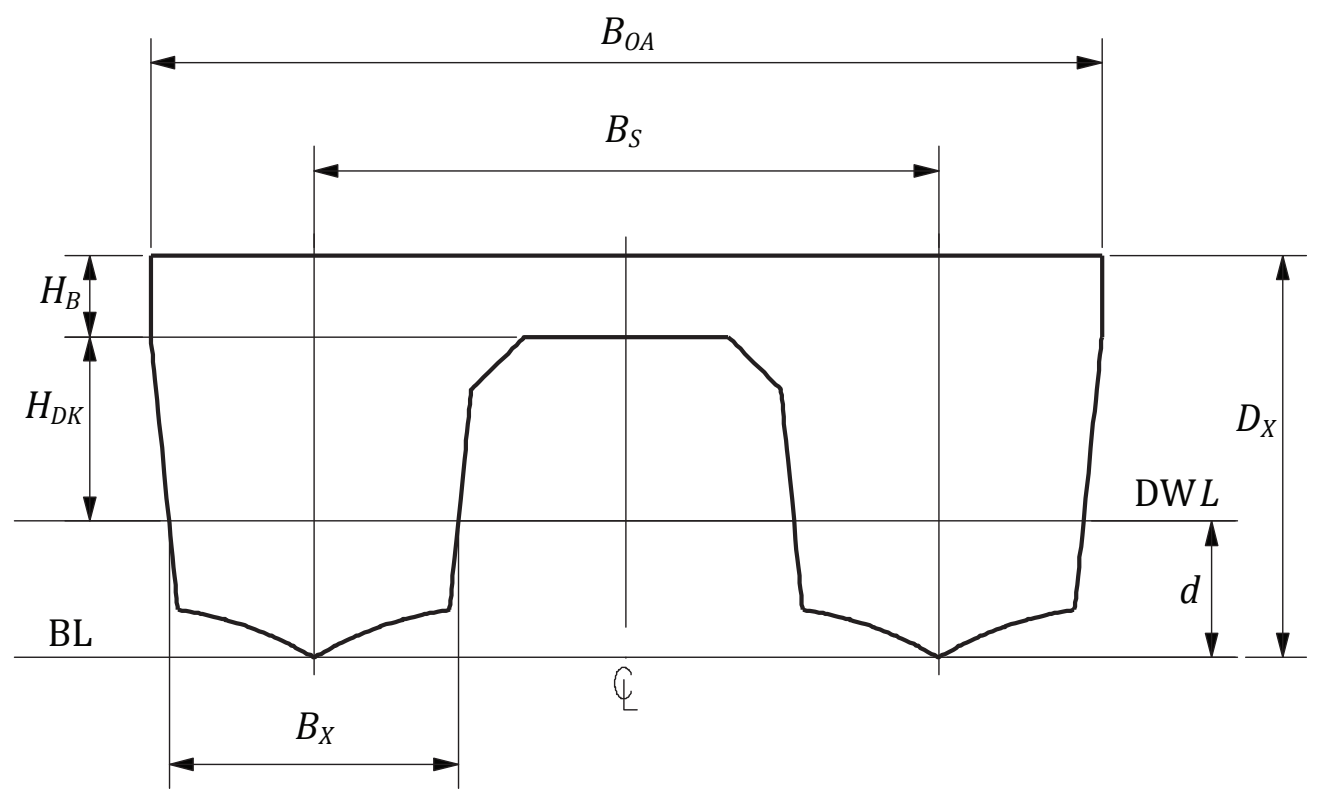

Figure 2 Determining the Catamaran Dimensions

The WFSV main dimensions (Figure 2) are determined according to the following dependences:

Length of waterline $[\mathrm{m}]$ :

$L_{W L}=0,9274 L_{H}-0,5503$

Beam of the demi-hull at the designed waterline (DWL) $[\mathrm{m}]$ :

$B_{X}=L_{W L} / x_{5}$

Demi-hull displacement volume $\left[\mathrm{m}^{3}\right]$

$\nabla_{1}=\left(\frac{L_{W L}}{l}\right)^{3}$

Catamaran displacement mass [t]:

$\Delta=2 \rho_{w} \nabla_{1}$

Draft $[\mathrm{m}]$ :

$d=B_{X} / x_{3}$

Hull spacing (distance between hull centre lines) [m]:

$B_{S}=L_{W L} X_{4}$

Beam overall $[\mathrm{m}]$ :

$B_{O A}=B_{S}+B_{X}$

Depth of hull to the main deck [m]:

$D_{X}=d+H_{D K}+H_{B}$

Block coefficient

$C_{B}=\frac{\nabla_{1}}{L_{W L} B_{X} d}$

Cross bridge height $[\mathrm{m}]$ :

$H_{B}=0,0648 e^{0,2977 B_{O A}}$
Wet deck clearance at maximal section [m]:

$$
H_{D K}=k \frac{h_{1 / 3}}{2}
$$

where is:

$h_{1 / 3}$ - significant wave height [m];

$k$ - coefficient determined on the basis of the statistical data, $\mathrm{k}>1$.

The obtained values of the main dimensions of the vessel are further used in Block 2 for the calculation of resistance and power of the main engines.

The determination of the main engines power can be carried out by using various familiar methods used when calculating the propulsion of high speed catamarans. This model implements the method published in [15], whereby resistance in still water is calculated by the following formula:

$$
R_{T}=R_{F}+\left(\varepsilon_{R} \nabla \rho_{W} g\right)
$$

where is:

$$
\begin{aligned}
& R_{F} \text { - friction resistance }[\mathrm{kN}] ; \\
& \nabla \text { - volume displacement }\left[\mathrm{m}^{3}\right] ; \\
& g \text { - gravity acceleration }\left[\mathrm{m} / \mathrm{s}^{2}\right] ; \\
& \rho_{W} \text { - density of sea water }\left[\mathrm{t} / \mathrm{m}^{3}\right] ; \\
& \varepsilon_{R}-\text { residuary drag-weight ratio: } \\
& C_{B}=\frac{\nabla_{1}}{L_{W L} B_{X} d}
\end{aligned}
$$

Values of the regression equation coefficients $X_{R}$ and the residual resistance coefficient $C_{R}$ are given in [15].

The installed power of the main engines can be calculated as follows [kW]: 


$$
P_{S}=\frac{R_{T} V}{\eta_{D} \eta_{G} \eta_{S}}\left(1+M_{s}\right)
$$

where is:

$\eta_{D}$ - quasi-propulsive efficiency coefficient;

$\eta_{G}$ - gearing efficiency;

$\eta_{s}$ - shafting efficiency;

$M_{S}$ - coefficient of sea margin.

The algorithm of calculation $\eta_{D}$ given in the publication [14] is used for water jets, and the one published in [9] is used for propellers.

The calculation of full displacement is performed according to the following dependence:

$$
\Delta=W_{L S}+D W
$$

where is:

$\Delta$ - full displacement [t];

$W_{L S}$ - lightship mass [t];

$D W$ - deadweight $[\mathrm{t}]$.

WFSV deadweight can be calculated by the use of the following relation:

$$
\begin{aligned}
& D W=W_{P L}+W_{F O i l}+W_{C R}+W_{F W}+W_{G R}+W_{T E}+ \\
& +W_{B W}+W_{C R G}+W_{T A S}
\end{aligned}
$$

where is:

$W_{P L}$ - maintenance technicians mass $[\mathrm{t}]$;

$W_{\text {Foil }}-$ fuel oil mass $[\mathrm{t}]$

$W_{C R}-$ crew mass [t];

$W_{F W}-$ fresh water mass $[\mathrm{t}]$

$W_{G S}-$ general stores mass [t] ;

$W_{T E}$ - mass of technician's equipment [t];

$W_{B W}-$ black water mass $[\mathrm{t}]$

$W_{C R G}-$ deck cargo mass [t];

$W_{\text {TAS }}$ - Turbine Access System (TAS) mass [t]

The algorithm for determining items of the lightship displacement of WFSV is based on the data given in the articles $[3,7]$. According to them, the lightship displacement $W_{L S}$ is calculated as a sum of the following items: the hull mass $W_{\text {Hull }}$ the machinery mass $W_{M}$, the outfit mass $W_{\text {Out }}$ and the sea margin mass $W_{S M}$ :

$$
W_{L S}=W_{\text {Hull }}+W_{M}+W_{\text {out }}+W_{S M}
$$

The hull mass is equal to [t]:

$$
W_{\text {Hull }}=W_{\text {Str }}+W_{\text {Sps }}
$$

The catamaran hull structures mass depends on the material and is calculated by using the following formula [t]:

$$
W_{S t r}=k_{2}\left(W_{100}+W_{T F}\right)
$$

where is:

$k_{2}$ - compensation for structural mass (welding, inserts, doublers, local stiffening). Is in range 1,05-1,125;

$W_{100}=q_{a l} S_{R} / 1000$ - stiffened plating mass $[\mathrm{t}] ;$

$q_{a l}=4,2 C_{N}^{0,3}$ - specific stiffened plating mass $\left[\mathrm{kg} / \mathrm{m}^{2}\right]$;

$C_{N}=L_{W L}\left(2 B_{X} D_{X}+\left(B_{S}-B_{X}\right) H_{B}\right)-$ cubic number for catamarans $\left[\mathrm{m}^{3}\right]$;
$W_{T F}=k_{1} W_{100}$ - the mass of the transverse web framing of the hull $[\mathrm{t}]$.

The coefficient $k_{1}$ takes into account the mass of the transverse framing. The values of $k_{1}$ are recommended to take in the range $0,25 \ldots 0,30$.

The calculation of the total reduced surface area $S_{R}$ has been executed in the way of the identification of the surface area of the bottom $S_{1}$, sides $S_{2}$, decks $S_{3}$, bulkheads $S_{4}$ and cross bridge $S_{5}[3]$

$$
\begin{aligned}
& S_{1}=2 \nabla_{1}^{1 / 3}\left(3,51 \nabla_{1}^{1 / 3}+0,568 L_{W L}\right)\left[\mathrm{m}^{2}\right] \\
& S_{2}=2,1\left(L_{O A}+L_{W L}\right)\left(D_{X}-d\right)\left[\mathrm{m}^{2}\right] \\
& S_{3}=2,3 L_{O A} B_{O A}\left[\mathrm{~m}^{2}\right] \\
& S_{4}=1,3 N_{W T B} C_{M} B_{X} D_{X}\left[\mathrm{~m}^{2}\right] \\
& S_{5}=0,92 L_{W L}\left(B_{S}-1,4 B_{X}\right)\left(1,96+H_{B}\right)\left[\mathrm{m}^{2}\right]
\end{aligned}
$$

where is:

$L_{O A}$ - length overall [m];

$N_{\text {WTB }}$ - number of watertight bulkheads;

$C_{M}$ - maximum transverse section coefficient;

The total reduced surface area $S_{R}\left[\mathrm{~m}^{2}\right]$ :

$$
S_{R}=S_{1}+0,73 S_{2}+0,71 S_{3}+0,67 S_{4}+0,81 S_{5}
$$

The mass of the superstructure can be calculated as follows:

$W_{S p s}=g_{S p s} \nabla_{S p s}, \mathrm{t}$

where is:

$g_{s p s}$ - specific mass of superstructure $\left[\mathrm{t} / \mathrm{m}^{3}\right]$;

$\nabla_{S p s}$ - superstructure volume $\left[\mathrm{m}^{3}\right]$.

The outfit mass is obtained by using the following formula:

$$
W_{\text {Out }}=0,03 L_{O A} B_{O A}
$$

The machinery mass is calculated by using the equation:

$$
W_{M}=W_{P}+W_{R m}
$$

where is:

$W_{P}$ - total propulsion mass: $W_{P}=W_{D}+W_{G B}+W_{W j}$;

$W_{D}$ - main engine mass [t];

$W_{G B}$ - gearboxes mass [t];

$W_{W J}$ - water jet or propeller or IPS mass [t];

$W_{R m}=0,55 W_{P}$ - remaining machinery mass (other mechanisms and the power plant equipment).

Mass of the main engines:

$$
W_{D}=5687,8\left(\frac{P_{S}}{R P M}\right)+182,11
$$

where is:

$P_{S}$ - installed power of main engines $[\mathrm{kW}]$.

$R P M$ - number of main engine revolutions $[\mathrm{r} / \mathrm{min}]$. 
At the initial stages of design, the gearboxes mass is calculated by using the following relation [7]:

$$
W_{G B}=0,00348 \cdot P_{S}^{0,75}[\mathrm{t}]
$$

The total mass of water jets:

$$
W_{W J}=0,0725 \cdot P_{s}^{1,3587}[\mathrm{~kg}]
$$

If on board the WFSV propellers are used as propulsion, that is why the following formula can be used for their mass calculation:

$$
W_{F P P}=1,1 D_{P}^{3} \frac{A_{E}}{A_{0}}[\mathrm{t}]
$$

where is:

$D_{p}$ - diameter of propeller [m];

$A_{E} / A_{0}$ - Expanded Area Ratio.

Mass propulsion of the IPS type:

$W_{\text {IPS }}=443,74 e^{0,0027 P_{S}}[\mathrm{~kg}]$

As a rule, the displacement margin is given in the percentage of the full displacement of the vessel $\Delta$ :

$$
W_{S M}=0,025 \Delta[\mathrm{t}]
$$

The assessment of the cost of the vessel construction at the initial stage of designing is performed according to the correlations [8]:

$$
C_{T A}=C_{e s t}+C_{e q}+C_{m a}
$$

where is:

$C_{\text {est }}$ - structure cost [GBP];

$C_{e q}$ - equipment costs [GBP]

$C_{m a}$ - machinery cost [GBP].

The structure cost is the sum of the structure material costs and labor cost:

$$
C_{\text {est }}=\left[1,1 W_{\text {Hull }} M\right]+\left[W_{\text {Hull }} L_{\text {Work }} H\right]
$$

where is:

$M$ - unit cost of structural material [GBP/t];

$H$ - unit cost of the man-hours [GBP/hours];

$L_{\text {Work }}$ - number of man-hours spent [man-hours].

The cost of machinery is equal to

$$
C_{m a}=1,4\left(C_{D}+C_{G B}+C_{W J}\right)
$$

where is:

$C_{D}$ - cost of the main engines [GBP];

$C_{G B}$ - cost of gear boxes [GBP];

$C_{W J}$ - cost of water jets or propellers [GBP].

To calculate the cost of equipment, the following formula is used:

$$
C_{e q}=\sum_{j=1}^{K} c_{j} W_{j}
$$

where is:

$W_{j}$-mass of the $j$-th item [t];

$c_{j}$ - unitary cost of the $j$-th mass item material $[\mathrm{GBP} / \mathrm{t}]$;

$K$ - number of mass items.

To assess the WFSV cost efficiency indicators, the author has developed an original technique, which has been based on the statistical modeling framework and the theory of probability.

The technique involves the use of the chart of the wind farm for which the optimal principal particulars of service vessels need to be determined (Figure 3). The specified characteristics include the number of wind turbines in the park, the distance from the park to the facility of the service vessels location, the distance between the wind turbines and the scheme of their layout.

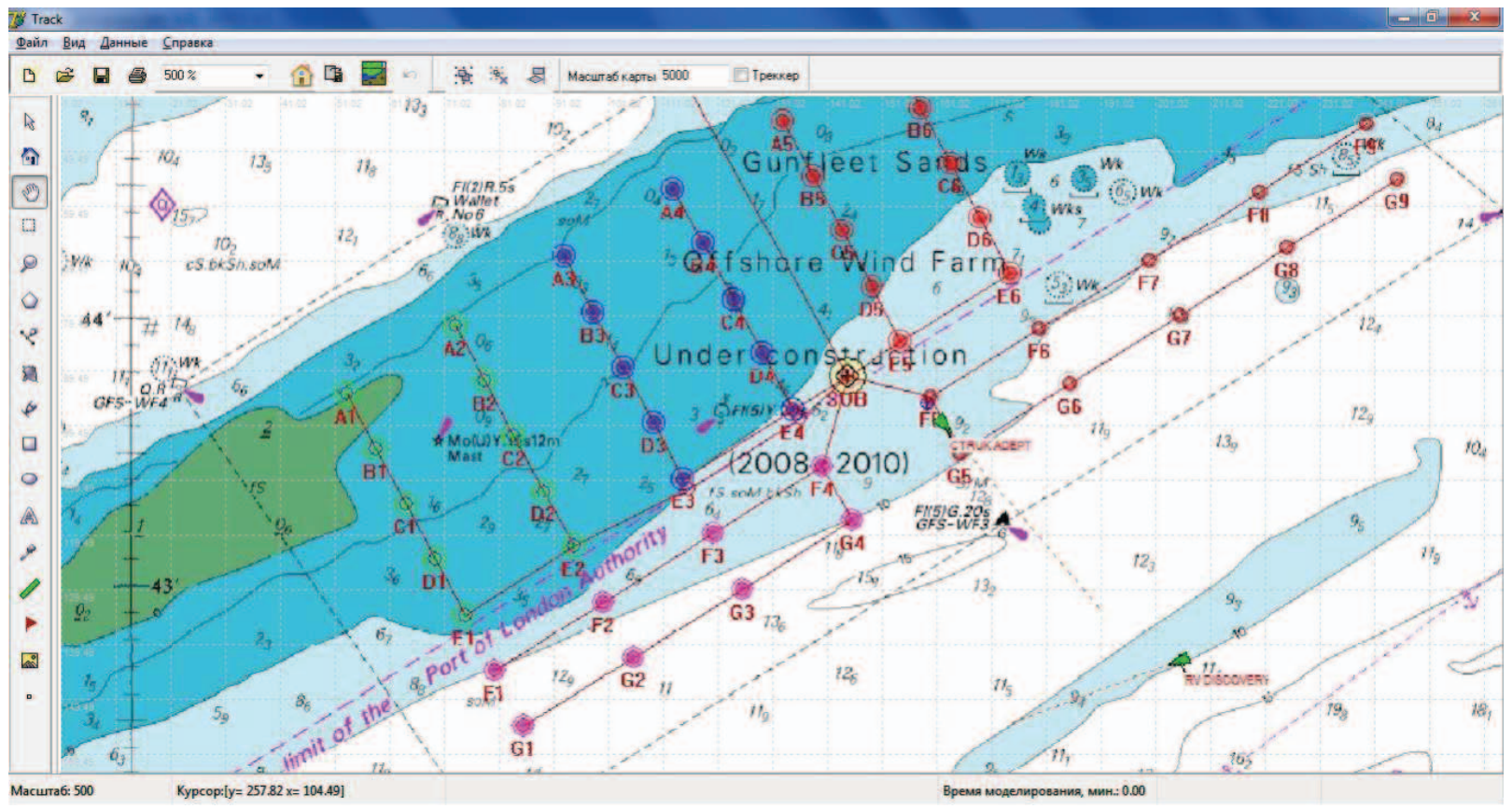

Figure 3 The Main Dialog Window of the Programme to Visualize the Process of the Functioning of WFSV and Wind Farm 
It is expected that the vessels can make a voyages in daytime at the wave height and the wind speed not exceeding the maximum permissible value. Attendance of the maintenance technicians takes place in the event of emergency or some wind turbine failure. The list of possible failures, the time required for fixing them, and the number of technicians required for the repair, are set on the basis of studying the statistical data (see Table 1). It is anticipated that the probability of the turbines breakdown or failure is the same for the entire wind farm.

The position of each wind farm turbine is set using the corresponding coordinates. Further on, the computer modelling of the wind farm functioning is performed, which accounts for possible emergency events and failures of the turbines. The flow of emergency events (failure rate) for the wind farm life cycle is presented in the form of the Weibull distribution [2]:

$$
h(t)=\rho \beta t^{\beta-1}
$$

where is:

$\beta$ - shape parameter;

$\rho$ - scale parameter.

The modeling of emergency or repair takes place according to the following algorithm. At any given time a uniformly distributed random number, $R$, in the interval 0 to 1 is generated and used to determine if a failure has occurred using the criteria (46). The event of the turbine failure is considered to have occurred when [2]

$$
R>[1-h(t)] \frac{\delta t}{8760}
$$

If it happens in working time and weather conditions allow for repair, the vessel voyage and the turbine repair are simulated. With the use of the chart, the distance of the vessel transfer Dist is determined. Then the following values are calculated:

- the additional resistance in a seaway taking into account the current weather conditions $R_{A W_{i}}$;

- the vessel speed loss in a seaway;

- the time of the technicians transfer $T_{S_{i}}=$ Dist $/ V_{a_{i}}$;

- the varying constituents of the operational expense of the vessel $C_{S}$;

- the coefficient of the operational service of the vessel.

When calculating the time of the personnel transfer the current weather conditions in the area of the wind farm are taken into account and the vessel speed in a seaway is determined:

$$
V_{a_{i}}=V_{0}-\delta V_{i}
$$

where is:

$V_{0}$ - vessel speed in still water [kn];

$\delta V_{i}$ - coefficient taking into account the speed losses in a seaway:

$$
\frac{\delta V_{i}}{V_{0}}=\sqrt{1+\frac{R_{A W_{i}}}{R_{T_{i}}}}
$$

where is:

$R_{A W_{i}}$-additional wave resistance for the $i$-th time step $[\mathrm{kN}]$;

$R_{T_{i}}$ - total resistance of the vessel in still water [kN].

If the emergency happens in a non-working time or at unsuitable weather conditions, the downtime is simulated, and the wind farm losses resulting from the broken turbine downtime are determined by means of the equation (46).

The suggested technique has been implemented in the form of the software complex enabling the visualization of the entire process of the WFSV operation during a specified period.

\section{Conclusion}

The developed technique allows the selection of the optimal principal particulars for the wind farm service vessels using the integrated criterion which takes into account the actual operating conditions and minimizes the maintenance costs and economic losses due to the turbine failures and delays in their repair.

The suggested technique of the selection of the optimal WFSV principal particulars is applicable to the conceptual design of catamarans. At the same time, it can easily be used for other WFSV types by modifying the mathematical model of the vessel.

The obtained results can also be implemented in design organizations for the determination of the WFSV main dimensions and the selection of the optimal wind farm maintenance strategy.

\section{References}

[1] Chan, V., Malmborg, Charles J.: Theory and Applications of Monte Carlo Simulations, InTech, Rijeka, 2013.

[2] Dalgic, Y.: Optimum CTV fleet selection for offshore wind farm O\&M activities. Safety and Reliability: Methodology and Applications, London, 2014, pp. 1177-1185.

[3] Grubisic, I.: Reliability of Weight Prediction in the Small Craft Concept Design, Proceedings of the 6th international conference on high-performance marine vehicles «HIPER 2008», Naples, 2008, pp. 215-226.

[4] Jupp, M., Sime, R., Dudson, E.: XSS - A Next Generation Windfarm Support Vessel, International Conference «Design \& Operation of Wind Farm Support Vessels», London, 2014.

[5] Kahrobaee, S., Asgarpoor, S.: Risk-Based Failure Mode and Effect Analysis for Wind Turbines (RB-FMEA), Proceedings of the North American Power Symposium (NAPS), Boston, USA, 2011, pp. 1-7.

[6] Law, A. M.: Simulation modeling and analysis: 5th edition, McGraw-Hill Publ., New York, 2015.

[7] Molland, A. F., Karayannis, T., Taunton, D. J., Sarac-Williams, Y.: Preliminary estimates of the dimensions, powering and seakeeping characteristics of fast ferries, International marine design conference IMDC, Athens, Greece, 2003, pp. 47-60.

[8] Moraes, H. B., Vasconcellos, J. M., Almeida, P. M.: Multiple criteria optimization applied to high speed catamaran preliminary design, Ocean Engineering, 34 (2007), pp. 133-147. 
[9] Oosterveld, M., Oosamen, P.: Further Computer Analyzed Data of the Wageningen B-Screw Series, International Shipping Progress, 22 (1975), 251, pp. 3-14.

[10] Rutkovskaya, D., Pilinskiy, M., Rutkovskiy, L.: Neyronnye seti, geneticheskie algoritmy i nechetkie sistemy [Neural networks, genetic algorithms and fuzzy systems], Goryachaya liniya - Telekom Publ., Moscow, 2013.

[11] Ryabinin, I.A.: Nadezhnost i bezopasnost strukturno-slozhnykh sistem [Reliability and safety of the structurally complex systems], Sankt Petersburgskogo universiteta Publ., Saint Petersburg, 2007.

[12] Sovetov, B.Ya., Yakovlev, S.A.: Modelirovanie sistem [System modeling], Vysshaya shkola Publ., Moscow, 2009.
[13] Stewart, W. J.: Probability, Markov Chains, Queues, and Simulation: The Mathematical Basis of Performance Modeling, Princeton University Press, Princeton, 2009.

[14] Van Terwisga, J. C.: A parametric propulsion prediction method for waterjet driven craft, Proceedings of the 4th International Conference on Fast Sea Transportation (FAST '97), Sydney, 1997, pp. 661-668.

[15] Zips, J. M.: Numerical Resistance Prediction based on the Results of the VWS Hard Chine Catamaran Hull Series «89», Proceedings of the Third International Conference on Fast Sea Transportation (Fast '95), Lubeck, Travemunde, Germany, 1995, pp. 67-74. 